\title{
Formation and fine-structures of nano-precipitates in ZIRLO
}

\author{
Gaihuan Yuan ${ }^{1,4}$, Guoqin Cao ${ }^{1,2,3 *}$, Qiang Yue ${ }^{4}$, Lei Yang ${ }^{2,3}$, Yifan Yun ${ }^{2,3}$, Guosheng \\ Shao ${ }^{1,2,3+}$, Junhua $\mathrm{Hu}^{1,2,3++}$
}

${ }^{1}$ Institute for Renewable Energy and Environmental Technologies, University of Bolton, Bolton BL3 5AB, UK

${ }^{2}$ School of Materials Science and Engineering, Zhengzhou University, Zhengzhou 450001, China

${ }^{3}$ State Centre for International Cooperation on Designer Low-carbon \& Environmental Materials, Zhengzhou University, 100 Kexue Avenue, Zhengzhou 450001, China

${ }^{4}$ State Nuclear Baoti Zirconium Industry Co., Ltd (SNZ), Baoji, 721013, China

Corresponding author: ${ }^{+}$G.Shao@bolton.ac.uk; ${ }^{++}$Hujh@zzu.edu.cn;

Co-first author ${ }^{*}$

Abstract: Transmission electron microscopy and energy dispersive X-ray spectroscopy have been used for crystallographic and compositional characterization of nano-precipitates distributed within the $\alpha$-Zr matrix of the ZIRLO alloy. Intermetallic nano-particles with the C14 Laves-phase structure were found to be the dominant precipitate phase typically larger than $60 \mathrm{~nm}$ in sizes, which is assigned to the $\mathrm{Zr}(\mathrm{Fe}, \mathrm{Nb})_{2}$ formula with $\mathrm{Fe}$ and $\mathrm{Nb}$ being mixed on the second sublattice sites in the bracket. Stacking faults were also observed in the ternary Laves phase, together with dislocations presenting on prism planes of the matrix solid solution. Besides, some fine spherical $\beta-\mathrm{Nb}$ particles about $30 \mathrm{~nm}$ in size were also found to precipitate within the $\alpha-Z r$ grains, with the $\alpha / \beta$ interface being crystallographically coherent.

Key words: $\mathrm{Zr}$ alloy; $\mathrm{Zr}-\mathrm{Fe}-\mathrm{Nb}$; nano-precipitates stacking fault; crystallographic characteristics 


\section{Introduction}

Nuclear energy has been considered as an effective means to power the modern world without the emission of carbon dioxide. Currently, almost $15 \%$ of the world's electricity consumption is generated from nuclear power. Zr-based alloys, or ZIRLO, have been used for fuel cladding tubes in nuclear reactors due to their low absorption cross-section for thermal neutrons, good mechanical properties and high corrosion resistance. There has been continuing effort in prolonging the service life of the fuel-cladding materials, in order to meet the challenging request for ever-increasing burn-up of nuclear reactors ${ }^{[1]}$. This can be achieved through the introduction of alloying elements with low absorption cross-section of thermal neutrons to induce solution and/or precipitate strengthening while maintaining good corrosion resistance. Therefore, only a limited number of alloying elements are suitable for cladding $\mathrm{Zr}$ alloys, with their acceptable contents being fairly low. So far the recognized alloying elements for such materials include $\mathrm{Nb}, \mathrm{Sn}, \mathrm{Fe}, \mathrm{Cr}, \mathrm{O}$ etc. The ZIRLO alloy is one of the few successfully developed and commercially applied alloys, which was introduced to pressurized water reactors in $1987^{[2]}$. The nominal ZIRLO composition (wt. \%) contains $1 \% \mathrm{Nb}, 1 \% \mathrm{Sn}$, and $0.1 \% \mathrm{Fe}$. In addition to the improvement of corrosion resistance achieved by ZIRLO cladding with respect to that of the Zircaloy-4 material, the in-service growth and creep were also significantly slower, resulting in an improved dimensional stability ${ }^{[3]}$. The compositions and crystalline structures of precipitates in ZIRLO are reckoned to be influenced by the solubility of $\mathrm{Nb}$ and $\mathrm{Fe}$ in $\alpha-\mathrm{Zr}$, as well as by the empirical ratio $\mathrm{R}=\mathrm{Fe} /(\mathrm{Fe}+\mathrm{Nb}-0.3 \%)^{[4]}$. As for the solubility limit of Sn, Toffolon-Masclet et al. updated the $\mathrm{Zr}$-Sn binary phase diagram through experimental investigation together with first-principle calculation, and thus reevaluated the $\mathrm{Sn}$ solubility limit in $\alpha-\mathrm{Zr}^{[5]}$. Based on their work there would be no Sn containing precipitates in ZIRLO. According to the parameter R proposed by Shishov, the precipitates should be the body-centered-cubic $\beta-\mathrm{Nb}$ and the hexagonal $\mathrm{Zr}-\mathrm{Fe}-\mathrm{Nb}$ phase. For the $\mathrm{Zr}-\mathrm{Fe}-\mathrm{Nb}$ phase, Granovsky ${ }^{[6]}$, Ramos ${ }^{[7]}$, Barberis ${ }^{[8]}$, and Toffolon-Masclet ${ }^{[9]}$ independently prepared some $\mathrm{Zr}$-Sn-Nb-Fe alloys, and carried out structural study of precipitated phases. They concluded that the $\mathrm{Zr}-\mathrm{Nb}-\mathrm{Fe}$ particles can be divided into FCC and HCP structures, the former space group was $F d \overline{3} m$ ( $\mathrm{Ti}_{2} \mathrm{Ni}$ type), while the latter had $P 6_{3} / m m c$ space group $\left(\mathrm{MgZn}_{2}\right.$ type, $\left.\mathrm{C} 14\right)$. 
When serving in nuclear reactors, the inner surface of cladding tubes is in contact with fission products at high temperature while the outer surface endures high temperature and high pressure water $\left(280 \sim 350{ }^{\circ} \mathrm{C}, 10 \sim 16 \mathrm{MPa}\right)$. In such a harsh working environment, the corrosion resistance of $\mathrm{Zr}$ alloys is very important. Numerous experiments have shown that the size distribution and type of second phase/s affect the penetration of oxygen ions and associated nodular corrosion. The optimized corrosion performance of $\mathrm{Zr}$ alloys was achieved when the fine second phase particles were uniformly precipitated in $\alpha-Z r$ matrix. Rudling et al. showed that the SPPs distribution and chemical composition heavily affected the corrosion behavior, since the barrier layer (dense zirconia) which influence the diffusion of oxygen ions was closely related to the SPPs ${ }^{[10]}$. On the other hand, the defects of precipitates make them prone to amorphization and elemental migration, which would change the stability of precipitates and chemical compositions of the matrix, thereby lowering the working performance of $\mathrm{Zr}$ alloys ${ }^{[11,12]}$.

While moderate incorporation of alloying elements such as $\mathrm{Fe}, \mathrm{Cr}$ and $\mathrm{Ni}$ etc within the $\alpha-\mathrm{Zr}$ may help strengthen the materials without evident negative impact on corrosion resistance, the precipitation of intermetallic compounds will occur when their contents are above the rather low solid solubility. The formation of such second phases rich in alloying elements will affect their mechanical properties, corrosion resistance and as well as possible hydrogen pickup process in service. It is therefore important to understand the precipitation process and associated crystallographic phenomena and compositional redistribution ${ }^{[13-16]}$. In spite of years of investigation, such data, particularly defect evolution and crystallographic details, are yet lacking for $\mathrm{Zr}$ alloys containing $\mathrm{Nb}$ and $\mathrm{Fe}$ as the main alloying element. This work is focused on the refined structural/crystallographic characterization of nano-precipitates in a thermomechanically processed ZIRLO alloy, with particular interest in orientation relationship, compositional redistribution across phases, defects formation and phase interfaces.

\section{Experimental Methods}

Ingots of alloys with the typical ZIRLO composition ( $\mathrm{Zr}-1$ wt.\% $\mathrm{Nb}-1 \mathrm{wt} . \% \mathrm{Sn}-$ $0.1 \mathrm{wt} . \% \mathrm{Fe}$ ) were prepared by vacuum arc melting, using a self-consuming electrode of the same composition to avoid impurity pickup. Each ingot was then forged at 
$1070{ }^{\circ} \mathrm{C}$ (in the $\beta$ phase field) into feeding blocks for subsequent thermal mechanical processing. The forged blocks were water-quenched down to room temperature. After surface cleaning each feeding block was subjected to hot rolling at $600{ }^{\circ} \mathrm{C}$ into sheets of $3.8 \mathrm{~mm}$ in thickness. After annealing at $600{ }^{\circ} \mathrm{C}$ for $2 \mathrm{~h}$, they were then cold rolled down to $0.8 \mathrm{~mm}$ in thickness. Finally the sheets were annealed at $600{ }^{\circ} \mathrm{C}$ for $3 \mathrm{~h}$ to obtain a fully recrystallized structure.

Thin foils for transmission electron microscopy (TEM) were mechanically polished to about $60 \mu \mathrm{m}$ in thickness, and then the central region of each disc was dimple-polished down to about $20 \mu \mathrm{m}$ in thickness. Twin-jet electro-polishing was then followed, using an electrolyte consisting of a solution of $10 \%$ perchloric acid and $90 \%$ ethanol. The working temperature for the electrolyte was maintained at $-40{ }^{\circ} \mathrm{C}$ and the working voltage was $45 \mathrm{~V}$. Finally, the foils were polished by ion milling at $5 \mathrm{eV}$, with a liquid nitrogen cooling stage. TEM and energy dispersive X-ray spectroscopy (EDS) were carried out at $200 \mathrm{kV}$, using a JEM 2010FEF microscope equipped with an energy dispersive X-ray (EDX) detector (Oxford UTW Isis).

\section{Result and discussion}

Fig. 1 shows bright field (BF) image typical of the microstructure of the ZIRLO alloy. The equiaxed morphology of $\alpha-\mathrm{Zr}$ grains indicate complete re-crystallization, and nano-precipitates are shown to distribute largely evenly across the gains of the matrix phase. The precipitates can be classified into two size groups, the larger precipitates (SPP1) above 60nm (mostly $60-80 \mathrm{~nm}$ ) in size and ultrafine nano-crystals below $30 \mathrm{~nm}$ in size (SPP2). EDS analysis showed that the larger precipitates (SPP1) contained similar atomic levels of $\mathrm{Zr}, \mathrm{Fe}$ and $\mathrm{Nb}$ without evidence of $\mathrm{Sn}$, and is thus a ternary $\mathrm{Zr}-\mathrm{Fe}-\mathrm{Nb}$ phase. While the size of the ultrafine precipitates (SPP2) are below the limit of the spatial resolution for EDS, EDS quantification with $1 \mathrm{~nm}$ electron probe centered on such ultrafine precipitates did indicate that even under the influence of the matrix composition, they were significantly richer in $\mathrm{Nb}$ than the former. This offers strong indication that the two kinds of precipitates are of different type of phases. This is consistent with the work of Toffolon-Masclet ${ }^{[5]}$, as the Zr-rich ZIRLO alloy is located within the three phase region $(\alpha-\mathrm{Zr}+\mathrm{C} 14+\beta-\mathrm{Nb})$ on the isothermal section at $550{ }^{\circ} \mathrm{C}$ of the $\mathrm{Zr}$ rich corner of the $\mathrm{Zr}-\mathrm{Nb}-\mathrm{Fe}$ phase diagram, as show in Fig. 2. This leads to $\mathrm{Zr}$ being the major phase of matrix and the other two phases being 
minor precipitates formed through precipitation from the $\mathrm{Zr}$ solid solution.

\section{$3.1 \beta-N b$}

Ultrafine spherical precipitates were observed within the grains of the matrix $\alpha-Z r$ phase (Fig. 3(a) ). EDS result shows that it contained more than 44 at. $\% \mathrm{Nb}$, considering the influence of the matrix phase composition. The solubility limit of $\mathrm{Nb}$ in $\beta-\mathrm{Zr}$ is about 36 at.\%, which is lower than the tested $\mathrm{Nb}$ content in the spherical phase, indicating that the spherical phase should be $\beta-\mathrm{Nb}^{[6]}$. Due to the low diffusion coefficient and low content of $\mathrm{Nb}$ in $\alpha-\mathrm{Zr}$, most $\mathrm{Nb}$ would be kept in the matrix phase to form supersaturated $\alpha-\mathrm{Zr}$, during quenching the alloy from the forging temperature in the $\beta-\mathrm{Zr}$ phase field. The precipitates including the ultrafine $\beta-\mathrm{Nb}$ particles were formed via a solid state precipitation process during thermomechanical processing and annealing at $600{ }^{\circ} \mathrm{C}$ when the alloy was in the three-phase field $(\alpha-\mathrm{Zr}+\mathrm{C} 14+\beta-\mathrm{Nb})$.

HRTEM study was carried out to study the refined crystallographic characteristics between the precipitates and the matrix phase. Fig. 3(b) shows a HREM image corresponding to the [0001] zone axis of the matrix phase, revealing excellent coherency at the interface, owing to small lattice mismatches between the hcp and bcc structures involved. The corresponding orientation relationship was $[0001]_{\alpha} / /[110]_{\beta}$ and $(1 \overline{100})_{\alpha} / /(1 \overline{11})_{\beta}$, which satisfies the so-called Burgers orientation relationship between hcp and bcc solid solution phases. Such typical Burgers orientation relationship is generic for alloys based on the group IV transition metals, such that it also holds in Ti alloys ${ }^{[17]}$.

\subsection{The ternary $\mathrm{Zr}-\mathrm{Fe}-\mathrm{Nb}$ precipitate}

Selected area electron diffraction (SAED) showed that the larger ternary SPP1 particles were of the hexagonal C14 Laves phase structure, being consistent with the alloy phase diagrams near the $600{ }^{\circ} \mathrm{C}$ thermomechanical processing temperature (Fig. 2). Fig. 4 shows the orientation relationship between the SPP1 C14 compound and the matrix, with a SAED pattern from the region of Fig. 4(a) containing two sets of low-index diffraction patterns from the matrix and a spherical SPP1 precipitate, respectively. The diffraction pattern from the matrix is at the $\alpha-\operatorname{Zr}$ [0001] zone axis, 
and that from the precipitate corresponds to the [0110] zone axis of the $\mathrm{C} 14$ phase. The orientation relationship is therefore near: $(2 \overline{110})_{\text {spp }} / /(1010)_{\alpha-z r},[0001]_{\alpha-z r} / /[0110]_{\text {spp. Fig. }}$. 4(c) shows the corresponding atomic illustration for such an orientation relationship. Using the $\alpha-Z r$ SAED pattern as an in situ reference, the lattice parameters of the precipitate was calculated to be $\mathrm{a}=0.559 \mathrm{~nm}, \mathrm{c}=0.842 \mathrm{~nm}$. The orientation relationship is only approximate, from the evidence that the precipitate was somewhat off the corresponding zone axis. This could be attributed to geometrical relaxation in reducing interface stress.

There was evidence for the existence of stacking faults in the C14 compounds, as is shown in Fig. 5(a), which reveals parallel lines corresponding to the traces of the habit planes for the faults. Corresponding diffraction pattern, Fig. 5(b), shows streaking in some spots along the [1010] vector, owing to the presence of stacking faults in the (1010) plane. The stacking fault was found before ${ }^{[18,19]}$, but the researchers did not specify the stacking fault plane. Usually, the formation of stacking fault is related with the moving of dislocation. The dislocations in alloys generally start at the most close-packed crystal plane. In a hexagonal phase with the c/a ratio being the ideal 1.633 value, the close-packed plane is $\{0001\}$. If the phase is not close packed, the \{0001\} plane may not be the most close-packed plane any more. Dislocations can then move preferentially on the prism $\{1010\}$ plane when it is the most closely packed. Even for the $\alpha-Z r$ phase, its c/a ratio is 1.593 . Interestingly, even for pure $\alpha-Z r$, the spacing of the prism plane $\{1 \overline{100}\}$ is $2.798 \AA$, while the spacing of its basal plane $\{0002\}$ is only $2.573 \AA$. So the prism plane for $\alpha-\mathrm{Zr}$ is most closely packed in the $\alpha-\mathrm{Zr}^{[20,21]}$. On the other hand, the c/a ratio of $\mathrm{C} 14 \mathrm{Zr}-\mathrm{Fe}-\mathrm{Nb}$ phase is only about 1.5 , making the prism planes the most closely packed. The orientation relationship between the $\mathrm{C} 14 \mathrm{Zr}-\mathrm{Fe}-\mathrm{Nb}$ phase and $\alpha-\mathrm{Zr}$ is, as noted above, $(21 \overline{10})_{\mathrm{spp}} /(10 \overline{10})_{\alpha-\mathrm{zr}}$. Presumably, dislocations could move from a matrix (1010) plane to a SPPs (2110) plane. However, because the (2110 ) plane is not the close-packed plane, dislocations tend to transfer to the $\{10 \overline{0} 0\}$ planes of the $\mathrm{Zr}-\mathrm{Fe}-\mathrm{Nb}$ phase. The dislocations can then cross slip between intersecting $\{10 \overline{0}\}$ planes, in a way similar to that between the closely packed $\{111\}$ planes in a face centered cubic phase, thus leading to dissociation of dislocations into partials with stacking fault in between. The trace of the habit planes will then exhibit as parallel lines such as observed in Fig. 5(a). 
EDS was used to quantify the contents of $\mathrm{Nb}$ and $\mathrm{Fe}$ in the $\mathrm{Zr}-\mathrm{Fe}-\mathrm{Nb}$ SPPs with different sizes (Fig. 6). Because SPPs are very small and embedded into the matrix, the characteristic X-rays generated from the matrix will also contribute to the results, with the high concentration of $\mathrm{Zr}$ in the matrix leading to most serious error in the analysis. We therefore only quantified the ratio of $\mathrm{Fe} / \mathrm{Nb}$ for the $\mathrm{C} 14$ phase, with the consideration that the rather low contents of $\mathrm{Nb}$ and $\mathrm{Fe}$ in the matrix would not lead to evident errors. A second phase with different sizes could represent different growth stages. The $\mathrm{Fe} / \mathrm{Nb}$ ratio of $\mathrm{Zr}-\mathrm{Fe}-\mathrm{Nb}$ phase varied with the increase of particle size (Fig. 7). The bigger the particle size, the smaller the ratio of Fe/ $\mathrm{Nb}$ became. When the particle size increased beyond $100 \mathrm{~nm}$, the ratio of $\mathrm{Fe} / \mathrm{Nb}$ is close to what Barberis et al. reported ${ }^{[22]}$, meaning that the SPPs were then largely in the stable state. This phenomenon confirmed that during the growth of $\mathrm{Zr}-\mathrm{Fe}-\mathrm{Nb}$ phase, elemental evolution was controlled by solid state diffusion. Due to the fact that Fe diffuses orders faster than $\mathrm{Nb}$ in $\alpha-\mathrm{Zr}\left(\mathrm{D}_{\mathrm{Nb}}=10 \times 10^{-21} \sim 10 \times 10^{-25} \mathrm{~m}^{2} / \mathrm{s}, \mathrm{D}_{\mathrm{Fe}}=10 \times 10^{-10} \mathrm{~m}^{2} / \mathrm{s}\right)^{[23]}$, the surrounding $\mathrm{Fe}$ atoms would diffuse into the $\mathrm{Zr}-\mathrm{Fe}-\mathrm{Nb}$ nucleus prior to $\mathrm{Nb}$. This led to higher $\mathrm{Fe}$ content than $\mathrm{Nb}$ in the initial growth state. Fig. 7 shows the relationship between $\mathrm{Fe} / \mathrm{Nb}$ ratio and particle size from data of this work and reported data from the literatures ${ }^{[24-26]}$. Although different manufacturing processes were adopted, all data showed the same trend in that the $\mathrm{Fe} / \mathrm{Nb}$ ratio decreases with increasing particle size in all samples.

As a class of phase structures due to geometrical packing of atoms of rather different sizes, the atomic configurations of Laves phases are dependent upon the relative atomic radii of the constituents. The atomic radii for $\mathrm{Zr}, \mathrm{Fe}$ and $\mathrm{Nb}$ are $\mathrm{R}_{\mathrm{Zr}}=0.216 \mathrm{~nm}$, $\mathrm{R}_{\mathrm{Nb}}=0.208 \mathrm{~nm}$, and $\mathrm{R}_{\mathrm{Fe}}=0.172 \mathrm{~nm}$, correspondingly. In the $\mathrm{AB}_{2}$ stoichiometry of the $\mathrm{C} 14$ Laves phase, $\mathrm{Zr}$ occupies the $4 \mathrm{f}$ site due to its large atomic radius, and $\mathrm{Fe}$ as the smaller atom occupies the $2 \mathrm{a}$ and $6 \mathrm{~h}$ sites. In the $\mathrm{Zr}-\mathrm{Fe}-\mathrm{Nb}$ system, it has been debatable however about the position of $\mathrm{Nb}$ atoms in the $\mathrm{C} 14$ Laves phase. In the late 1960s, Kanematsu ${ }^{[27]}$, Tanaka ${ }^{[28]}$, Alfieri ${ }^{[29]}$, Petkov ${ }^{[30]}$ proposed that laves phase (C14, $\mathrm{C} 15, \mathrm{C} 36)$ were of the atomic formula of $\left(\mathrm{Zr}_{1-\mathrm{x}}, \mathrm{Nb}_{\mathrm{x}}\right) \mathrm{Fe}_{2}$, with the $\mathrm{Zr}$ site being partially occupied by $\mathrm{Nb}$. On the basis of the valence electron concentration, they reported a cubic $\mathrm{C} 15$-type structure for $\mathrm{x}<0.35$ and a hexagonal $\mathrm{C} 14$-type structure 
for $\mathrm{x}>0.5$. However, recent experimental work by Ramos et al. showed that $\mathrm{Nb}$ mainly substitute $\mathrm{Fe}$ in the $2 \mathrm{a}, 6 \mathrm{~h}$ site in the $\mathrm{C} 14$ laves phase instead ${ }^{[7]}$. Ramos et al. obtained different compositions of the $\mathrm{C} 14$ compound by adjusting the contents of alloying constituents $\mathrm{Fe}$ and $\mathrm{Nb}$. The $\mathrm{Zr}$ content of the compound phase was found to be largely constant and the content of $\mathrm{Fe}$ and $\mathrm{Nb}$ varies inversely. This suggests that $\mathrm{Nb}$ preferred to occupy the positions of $\mathrm{Fe}$ atoms instead, which is consistent with the calculated phase diagram by Toffolon-Masclet et $\mathrm{al}^{[5]}$.

An effort was made in this work to test the latest phase equilibrium data ${ }^{[5,7]}$, with the preparation of an alloy close to the $\mathrm{C} 14$ composition in the $(\alpha-\mathrm{Zr}+\mathrm{C} 14+\beta-\mathrm{Nb})$ region at $550{ }^{\circ} \mathrm{C}$. Toffolon-Masclet ${ }^{[31]}$ observed that at $550{ }^{\circ} \mathrm{C}$ in the three-phase region $(\alpha-\mathrm{Zr}+\mathrm{C} 14+\beta-\mathrm{Nb})$ for the ternary $\mathrm{Zr}-\mathrm{Fe}-\mathrm{Nb}$ system, the atomic composition was nearly constant at $33.5 \mathrm{Zr}-38.5 \mathrm{Nb}-28 \mathrm{Fe}$ (at.\%). As this three-phase region is of particular interest to the ZIRLO alloy, here we prepared the alloy with the nominal composition of the melted alloy being $34 \mathrm{Zr}-38 \mathrm{Nb}-28 \mathrm{Fe}$ (at.\%), on the tip of the C14 ternary phase (marked as a black dot on the isothermal section of $\mathrm{Zr}-\mathrm{Nb}$-Fe ternary system at $900{ }^{\circ} \mathrm{C}^{[5]}$, Fig. 8a). The XRD spectra of the as-casted $\mathrm{C} 14$ compound and the referred standard PDF pattern are shown in Fig. 8(b) [5]. It can be seen that single $\mathrm{C} 14 \mathrm{Zr}-\mathrm{Fe}-\mathrm{Nb}$ phase was obtained.

Fig. 9 shows three diffraction patterns from different areas. It was found that the alloy only consisted of the $\mathrm{C} 14$ type $\mathrm{Zr}-\mathrm{Fe}-\mathrm{Nb}$ phase with composition being close to the nominal composition, indicating the great accuracy in the latest phase diagram. Fig. 10 shows an interface between two Zr-Fe-Nb grains. From the HRTEM of Fig. 10(b,d) it can be seen that both grains (A and B) had the hexagonal C14 structure and the zone axis are C14-[0110], C14-[0001], respectively. Fig. 10(c) clearly shows the two grains are coherently related, and the orientation relationship between two particles is A (0002)//B (1010); $\mathrm{A}[01 \overline{10}] / / \mathrm{B}[0001]$. It can be determined that $\mathrm{d} \mathrm{A}_{(0002)}=\mathrm{d}_{\mathrm{B}_{(1010)}}$. However, in the C14 structure, the spacing of $\{0002\}$ planes is slightly smaller than that of $\{10 \overline{10}\}$ planes. Thus, we conclude that the spacing of $\{0002\}$ plane in grain-A $(0.429 \mathrm{~nm})$ is larger than that in grain-B $(0.403 \mathrm{~nm})$, and the corresponding lattice constant of grain-A is larger than grain-B. From the perspective of components, grain-A has more $\mathrm{Nb}$ but less Fe compared with grain- $\mathrm{B}$, while the content of $\mathrm{Zr}$ is 
largely unchanged in both grains. Taking into account the atomic radius of $\mathrm{Fe}, \mathrm{Nb}, \mathrm{Zr}$ $\left(\mathrm{R}_{\mathrm{Zr}}=0.216 \mathrm{~nm}, \mathrm{R}_{\mathrm{Nb}}=0.208 \mathrm{~nm}, \mathrm{R}_{\mathrm{Fe}}=0.172 \mathrm{~nm}\right)$, we can conclude that the chemical composition of $\mathrm{C} 14$ type $\mathrm{Zr}-\mathrm{Fe}-\mathrm{Nb}$ phase should be $\mathrm{Zr}(\mathrm{Fe}, \mathrm{Nb})_{2}$, which means that the lattice constant will increase when $\mathrm{Nb}$ atoms replacing Fe. Thus it is reasonable to conclude that the formation of $\mathrm{Zr}-\mathrm{Fe}-\mathrm{Nb}$ precipitates can be attributed to the substitution of $\mathrm{Fe}$ at $2 \mathrm{a}, 6 \mathrm{~h}$ site by $\mathrm{Nb}$ in $\mathrm{C} 14$ laves phase.

The fact that the $\mathrm{Nb}$ and $\mathrm{Fe}$ contents could be swopped between two neighboring grains, while maintaining largely a constant $\mathrm{Zr}$ content, offers strong evidence that $\mathrm{Nb}$ and $\mathrm{Fe}$ can be readily mixed on the $\mathrm{B}$ sublattice sites of the $\mathrm{AB}_{2}$ stoichiometry of the C14 phase. As this phase structure does not exist as a stable phase in either the $\mathrm{Zr}-\mathrm{Fe}$ or the $\mathrm{Zr}-\mathrm{Nb}$ system, their coexistence is essential to stabilize such a structure in the $\mathrm{Zr}-\mathrm{Fe}-\mathrm{Nb}$ system. It is reasonable that the two later transition metals, $\mathrm{Nb}$ and $\mathrm{Fe}$, take the same B sublattice sites of the $\mathrm{C} 14$ phase, as both play a similar role in stabilizing the same crystal structure of the $\beta$ phase and thus are of rather different electronic nature from that of the group IV element $\mathrm{Zr}$.

\section{Conclusion}

This work shows that a $\mathrm{Zr}$ alloy with the typical ZIRLO composition lies in a three-phase equilibrium region containing the ground state phases of $\alpha-\mathrm{Zr}, \beta-\mathrm{Nb}$ and a ternary C14 Laves phase, which does not exist as an equilibrium phase in the constituent binary systems.

In the current thermomechanically processed material, the $\beta-\mathrm{Nb}$ and a ternary $\mathrm{C} 14$ Laves phases presented in the $\alpha$-Zr matrix as nano-precipitates. Ultrafine spherical $\beta-\mathrm{Nb}$ particles about $30 \mathrm{~nm}$ in size were found to precipitate within the $\alpha$ - $\mathrm{Zr}$ grains, with the $\alpha / \beta$ interface being crystallographically coherent, with a Brugers orientation relationship between the two phases.

Intermetallic nano-particles with the C14 Laves-phase structure were found to be the coarser precipitates typically larger than $60 \mathrm{~nm}$ in sizes, with the $\mathrm{Zr}(\mathrm{Fe}, \mathrm{Nb})_{2}$ stoichiometric formula wherein $\mathrm{Fe}$ and $\mathrm{Nb}$ are mixed on the second sublattice sites. Stacking faults were also observed in the ternary Laves phase. The orientation 
relationship between the Laves phase and the matrix was close to $(10 \overline{10})_{\alpha-\mathrm{zr}} / /(2 \overline{110})_{\mathrm{C} 14}$ and $[0001]_{\alpha-z r} / /[0110]_{C 14}$. The significant difference in the diffusion coefficients of $\mathrm{Fe}$ and $\mathrm{Nb}$ in the $\alpha-\mathrm{Zr}$ solid solution led to delayed enrichment of $\mathrm{Nb}$ in the $\mathrm{C} 14$ phase, with the $\mathrm{Nb} / \mathrm{Fe}$ ratio increasing during the coarsening of the Laves phase.

\section{Acknowledgement}

The authors acknowledge the financial support from the State Nuclear Baoti Zirconium Industry Company (SNZ) and the National Science Foundation of China (51001091, 111174256, 51571182, 52110774 and 91233101).

\section{Reference}

[1] H. G. Rickover, History of the development of zirconium alloys for use in nuclear reactors. Denver, Colo., March 1975.

[2] R. S. Kaiser, W. J. Leech, A. L. Cassadei, Proceedings, ANS International Topical Meeting on LWR Fuel Performance, Park City, UT, 2000.

[3] G. P. Sabol, R. J. Comstock, R. A. Weiner, et al. In-Reactor Corrosion Performance of ZIRLO and Zircaloy-4. Proceeding of the 10th International Symposium on $\mathrm{Zr}$ in the Nuclear Industry, ASTM STP 1245, 1994, 724.

[4] V. N. Shishov, M. M. Peregud, A. V. Nikulina, et al. Influence of structure-phase state of $\mathrm{Nb}$ containing $\mathrm{Zr}$ alloys on irradiation-induced growth. Proceeding of the 14th International Symposium on Zr in the Nuclear Industry, ASTM STP 1467, 2005, 666.

[5] C. Toffolon-Masclet, J. C. Brachet, C. Servant, et al. Contribution of thermodynamic calculations to metallurgical studies of multi-component zirconium based alloys. Proceeding of the 15th International Symposium on $\mathrm{Zr}$ in the Nuclear Industry, ASTM STP 1505, 2009, 754.

[6] M. S. Granovsky, M. Canay, E. Lena, et al. Experimental investigation of the Zr corner of the ternary Zr-Nb-Fe phase diagram. Journal of nuclear materials, 2002, 302(1), 1 .

[7] C. Ramos, C. Saragovi, M. S. Granovsky. Some new experimental results on the Zr-Nb-Fe system. Journal of nuclear materials, 2007, 366(1): 198.

[8] P. Barberis, E. Ahlberg, N. Simic, et al. Role of the second-phase particles in zirconium binary alloys, Proceeding of the 13th International Symposium on $\mathrm{Zr}$ in the Nuclear Industry, ASTM STP 1423, 2002, 33. 
[9] C. Toffolon-Masclet, J. C. Brachet, C. Servant, et al. Experimental Study and Preliminary Thermodynamic Calculations of the Pseudo-Ternary Zr-Nb-Fe- $(\mathrm{O}, \mathrm{Sn})$ System. Proceeding of the 13th International Symposium on $\mathrm{Zr}$ in the Nuclear Industry, ASTM STP 1423, 2002, 361.

[10] P. Rudling, G. Wikmark. A unified model of Zircaloy BWR corrosion and hydriding mechanisms, Journal of Nuclear Materials. 1999, 265, 44.

[11] G. Garzarolli, E. Steinberg, H. G. Weiginger. Microstructure and corrosion studies for PWR and BWR Zircaloy cladding. Proceeding of the 8th International Symposium on Zr in the Nuclear Industry, ASTM STP 1023, 1989, 202.

[12] J. Huang, M. Y. Yao, C. Y. Gao, et al. The influence of second phase particles on the crack formation in oxides films formed on zirconium alloys, Corrosion Science. $2015,99,172$.

[13] Y. Hatano, R. Hitaka, M. Sugisaki, et al. Influence of size distribution of $\mathrm{Zr}(\mathrm{Fe}$, $\mathrm{Cr})_{2}$ precipitates on hydrogen transport through oxide film of Zircaloy-4. Journal of nuclear materials, 1997, 248, 311.

[14] P. Yuan, M. Wei, Z. Fu, et al. Reactive vapor deposition and electrochemical performance of nano-structured magnesium silicide on silicon and silicon carbide substrates. Materials Science in Semiconductor Processing, 2014, 27, 873.

[15] J. Hu, C. Zhang, S. Guan, et al. Nanoporous $\mathrm{TiO}_{2}$ films prepared by thermal rapid treatment (TRT). Materials Letters, 2010, 64(23), 2569.

[16] G. Yuan, G. Cao, Q. Yue, et al. Formation of nanocrystalline $\delta-Z r H x$ in Zircoloy-4: Orientation relationship and twinning. Journal of Alloys and Compounds, 2016, 658, 494.

[17] G. Shao, P. Tsakiropoulos, A. P. Miodownik. Phase Transformations in Ti-40Al-10V. Intermetallics, 1995, 3, 315.

[18] V. N. Shishov, A. V. Nikulina, V. A. Markelov, et al. Influence of neutron irradiation on dislocation structure and phase composition of Zr-base alloys. Proceeding of the 11th International Symposium on $\mathrm{Zr}$ in the Nuclear Industry, ASTM STP 1295,1996, 603.

[19] G. Cao, L. Wang, Z. Fu, et al. Chemically anchoring of $\mathrm{TiO}_{2}$ coating on $\mathrm{OH}$-terminated $\mathrm{Mg}_{3}\left(\mathrm{PO}_{3}\right)_{2}$ surface and its influence on the in vitro degradation resistance of $\mathrm{Mg}-\mathrm{Zn}-\mathrm{Ca}$ alloy. Applied Surface Science, 2014, 308, 38.

[20] J. Hu, C. Zhang, B. Cui, et al. In vitro degradation of AZ31 magnesium alloy coated with nano $\mathrm{TiO}_{2}$ film by sol-gel method. Applied Surface Science, 2011, 
257(21), 8772.

[21] E. Tenckhoff. Review of deformation mechanisms, texture, and mechanical anisotropy in zirconium and zirconium base alloys. Proceeding of the 14th International Symposium on Zr in the Nuclear Industry, ASTM STP 1467, 2005, 25.

[22] P. Barberis. Influence of Small Nb Amounts on Microstructure and Properties of Zr-Nb-Sn-Fe Alloys. Journal of Nuclear Materials, 2004, 326, 163.

[23] G. M. Hood, R. J. Schultz. Diffusion of 3D Transition Elements in a-Zr and Zirconium Alloys. Proceeding of the 8th International Symposium on $\mathrm{Zr}$ in the Nuclear Industry, ASTM STP 1023, 1988, 435.

[24] Y. S. Kim, S. K. Kim, J. B. Bang, et al. Effects of $\mathrm{Sn}$ and $\mathrm{Nb}$ on massive hydriding kinetics of Zr-XSn-YNb alloy. Journal of nuclear materials, 2000, 279(2-3), 335.

[25] Y. H. Jeong, H. G. Kim, D. J. Kim, et al. Influence of Nb concentration in the $\alpha$-matrix on the corrosion behavior of $\mathrm{Zr}-\mathrm{xNb}$ binary alloys. Journal of Nuclear Materials, 2003, 323(1), 72.

[26] H. G. Kim, J. Y. Park, Y. H. Jeong. Phase boundary of the Zr-rich region in commercial grade $\mathrm{Zr}-\mathrm{Nb}$ alloys. Journal of nuclear materials, 2005, 347(1), 140.

[27] K. Kanematsu. Structural and megnetic properties of pseudobinary system $\left(\mathrm{Zr}_{1-\mathrm{x}} \mathrm{Nb}_{\mathrm{x}}\right) \mathrm{Fe}_{2}$. Journal of the Physical Society of Japan, 1969, 27(4), 849.

[28] M. Tanaka, N. Iio, T. Tokoro, K. Kanematsu. Mossbauer effect in $\left(\mathrm{Zr}_{\mathrm{x}} \mathrm{Nb}_{1-\mathrm{x}}\right) \mathrm{Fe}_{2}$. Journal of the Physical Society of Japan, 1968, 25(6), 1541.

[29] G. T. Alfieri, E. Banks, K. Kanematsu. Pressure dependence of the curie temperature of ferromagnetic laves phase alloy. Journal of Applied Physics, 1969, 40(3), 1322.

[30] V. V. Petkov, E. E. Cherkashin. Interaction between the Laves phase in quasi-binary sections of $\mathrm{ZrFe}_{2}-\left(\mathrm{NbFe}_{2}, \mathrm{TaFe}_{2}\right)$ and $\mathrm{ZrCo}_{2}-\left(\mathrm{NbCo}_{2}-\mathrm{TaCo}_{2}\right)$. Dopovidi Akademii Nauk Ukrains koi RSR, Seriya A: Fiziko-Tekhnichni ta Matematichni Nauki, 1972,32(3), 276.

[31] C. Toffolon-Masclet, P. Barberis, J.-C. Brachet, et al. Study of $\mathrm{Nb}$ and $\mathrm{Fe}$ Precipitation in $\alpha$-Phase Temperature Range (400 to $550{ }^{\circ} \mathrm{C}$ ) in $\mathrm{Zr}-\mathrm{Nb}-(\mathrm{Fe}-\mathrm{Sn})$ Alloys. Proceeding of the 14th International Symposium on $\mathrm{Zr}$ in the Nuclear Industry, ASTM STP 1467, 2005, 81. 


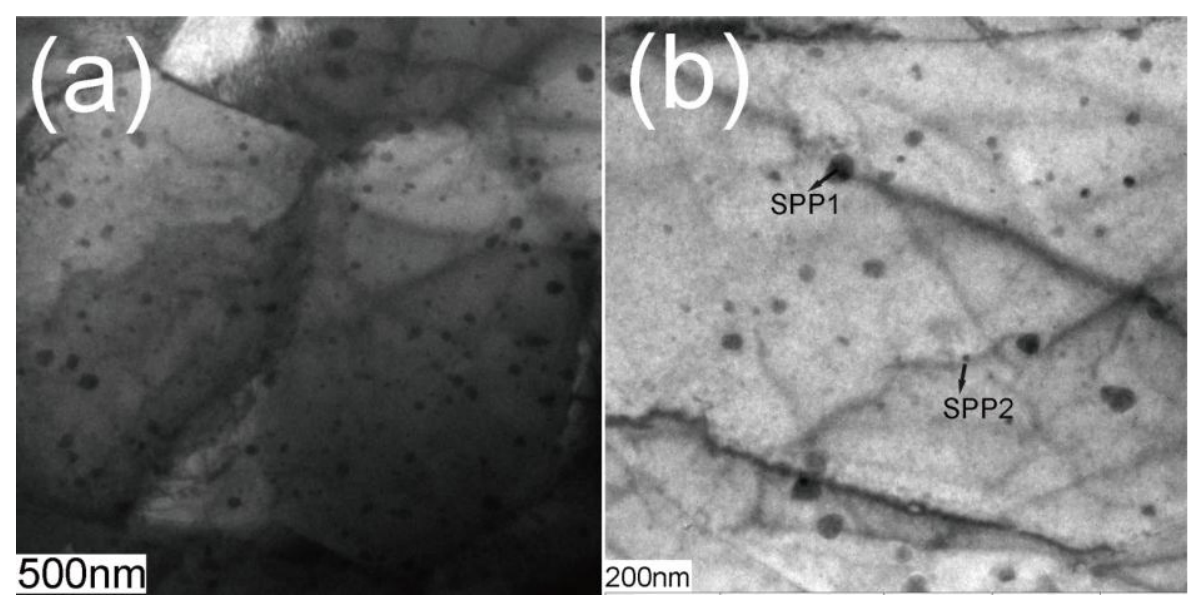

Fig. 1 


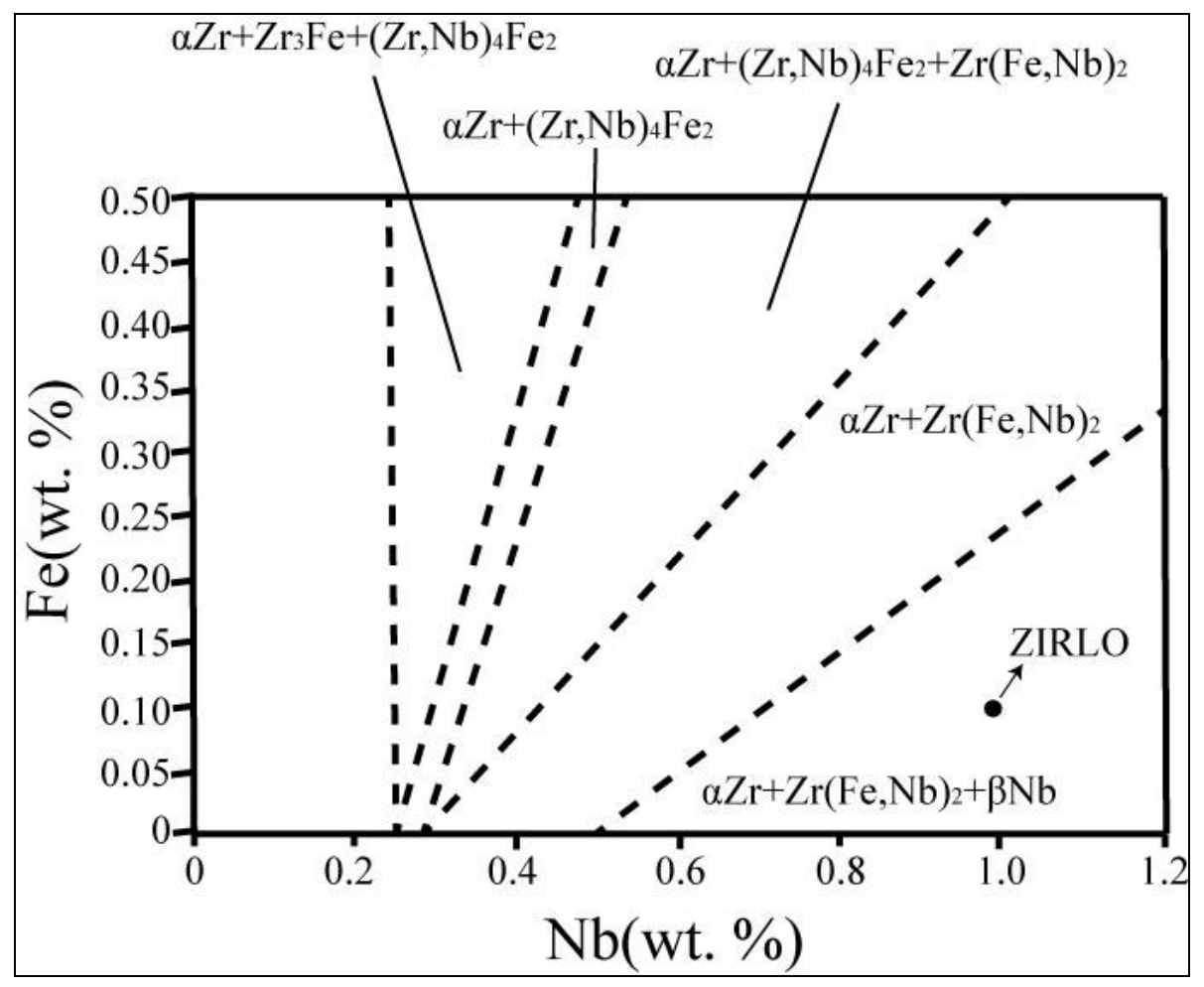

Fig. 2

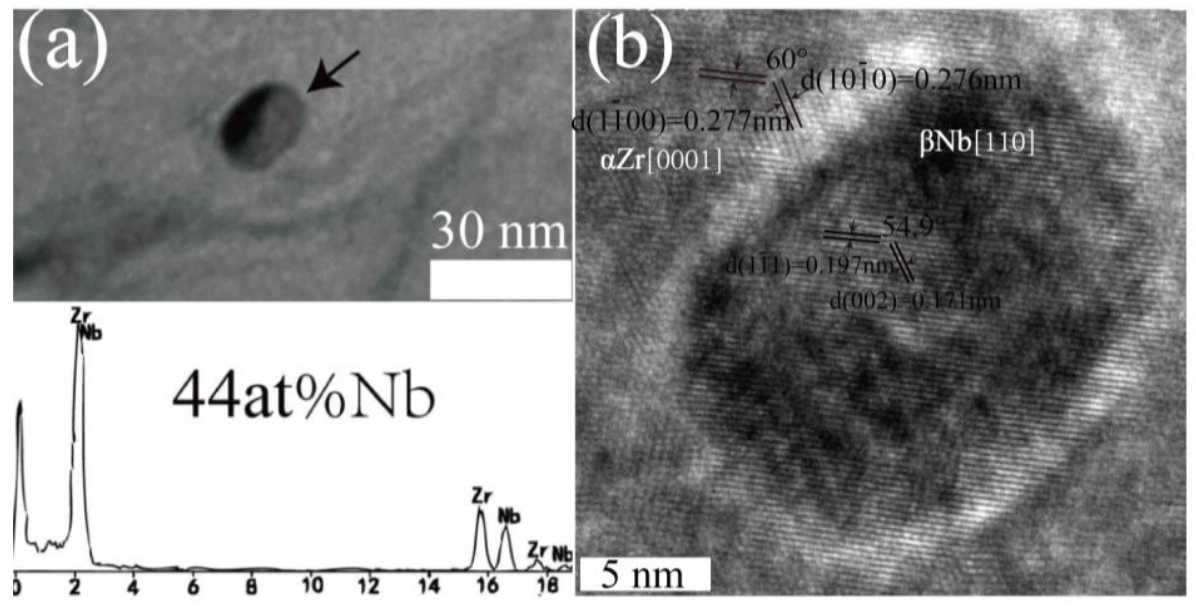

Fig. 3 

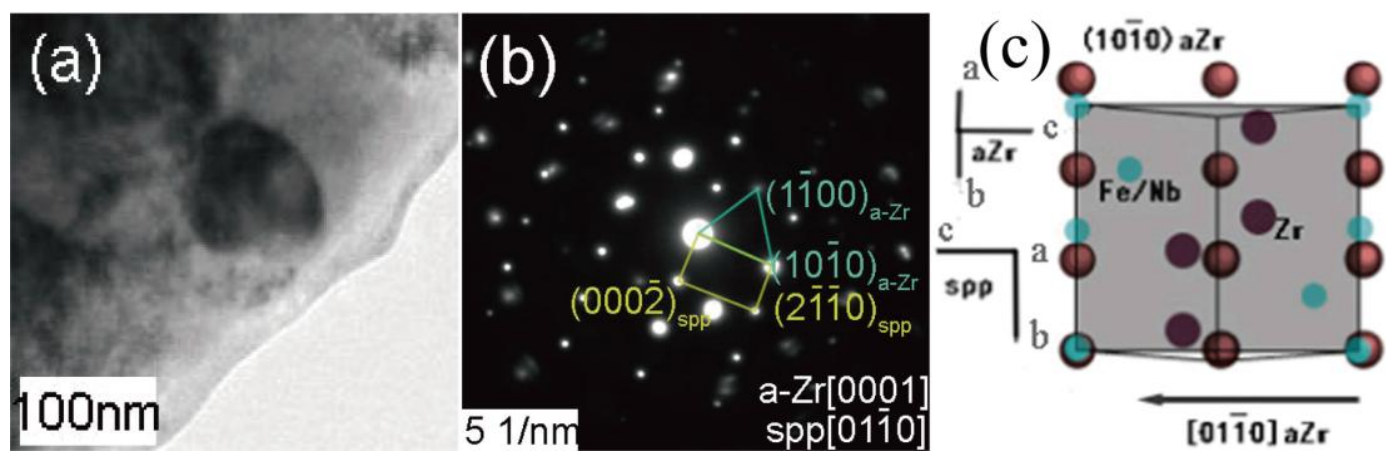

Fig. 4

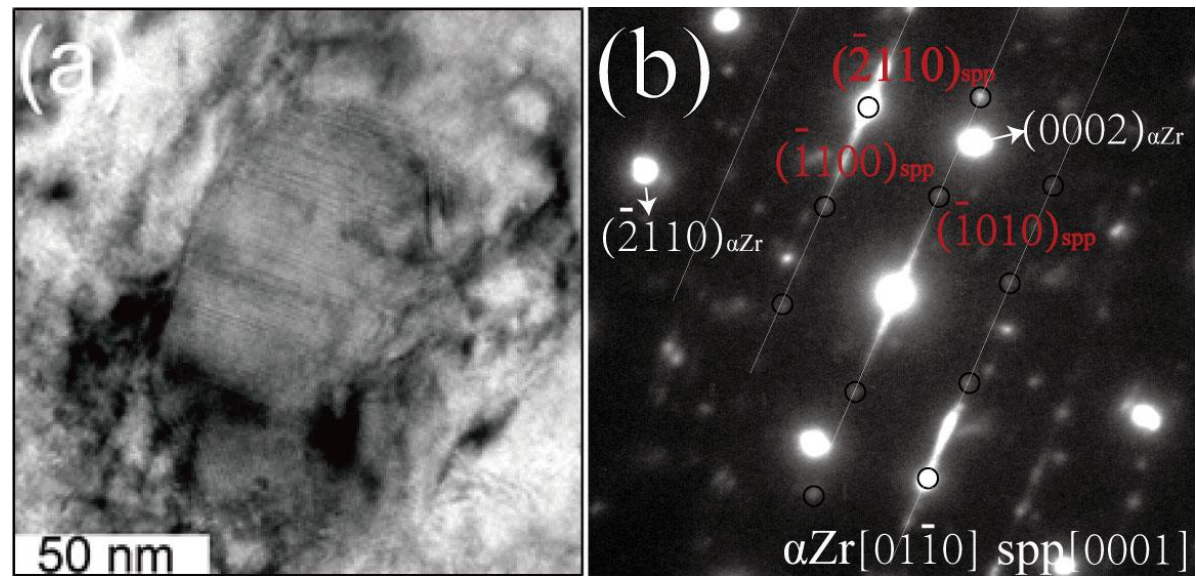

Fig. 5 


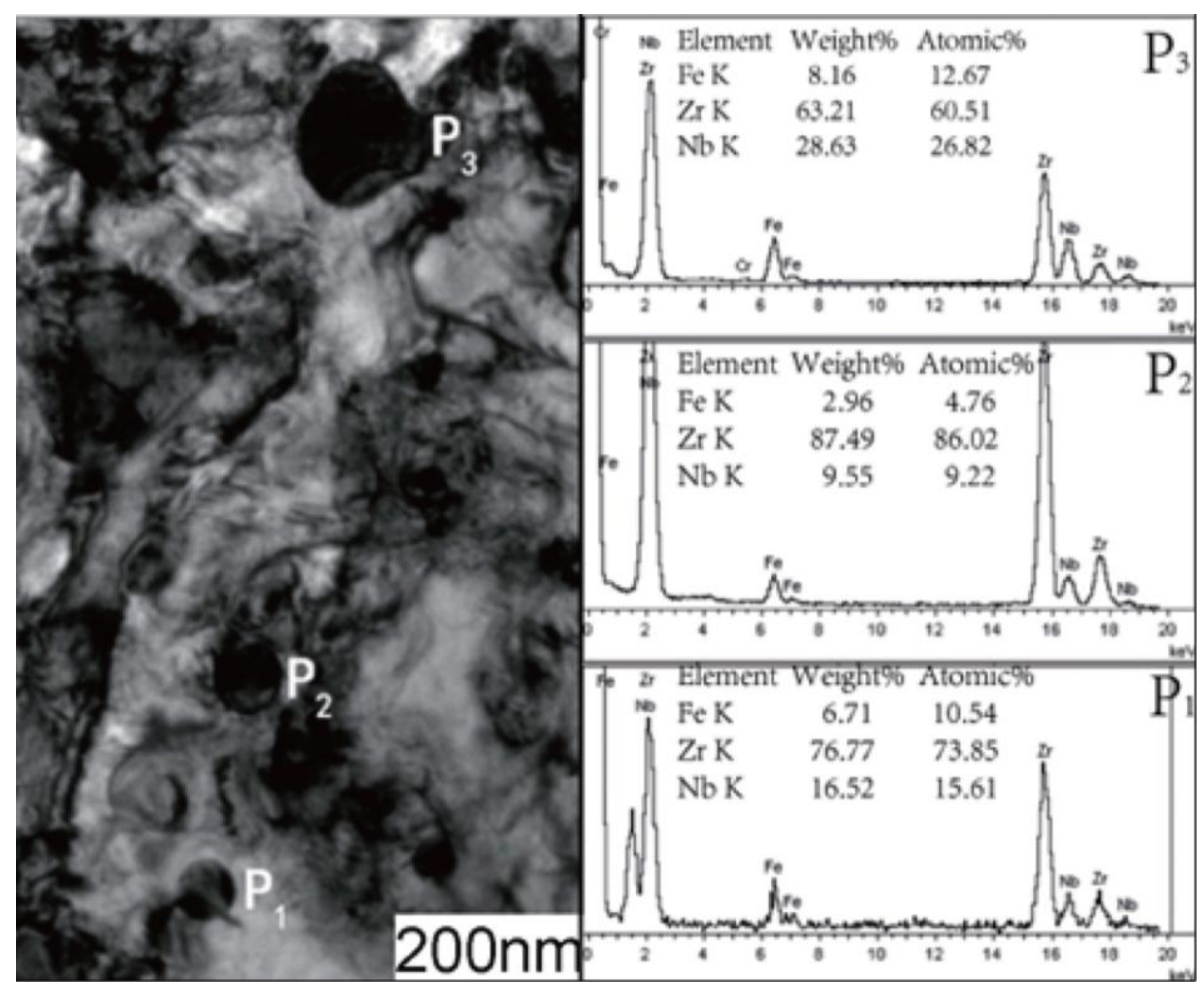

Fig. 6

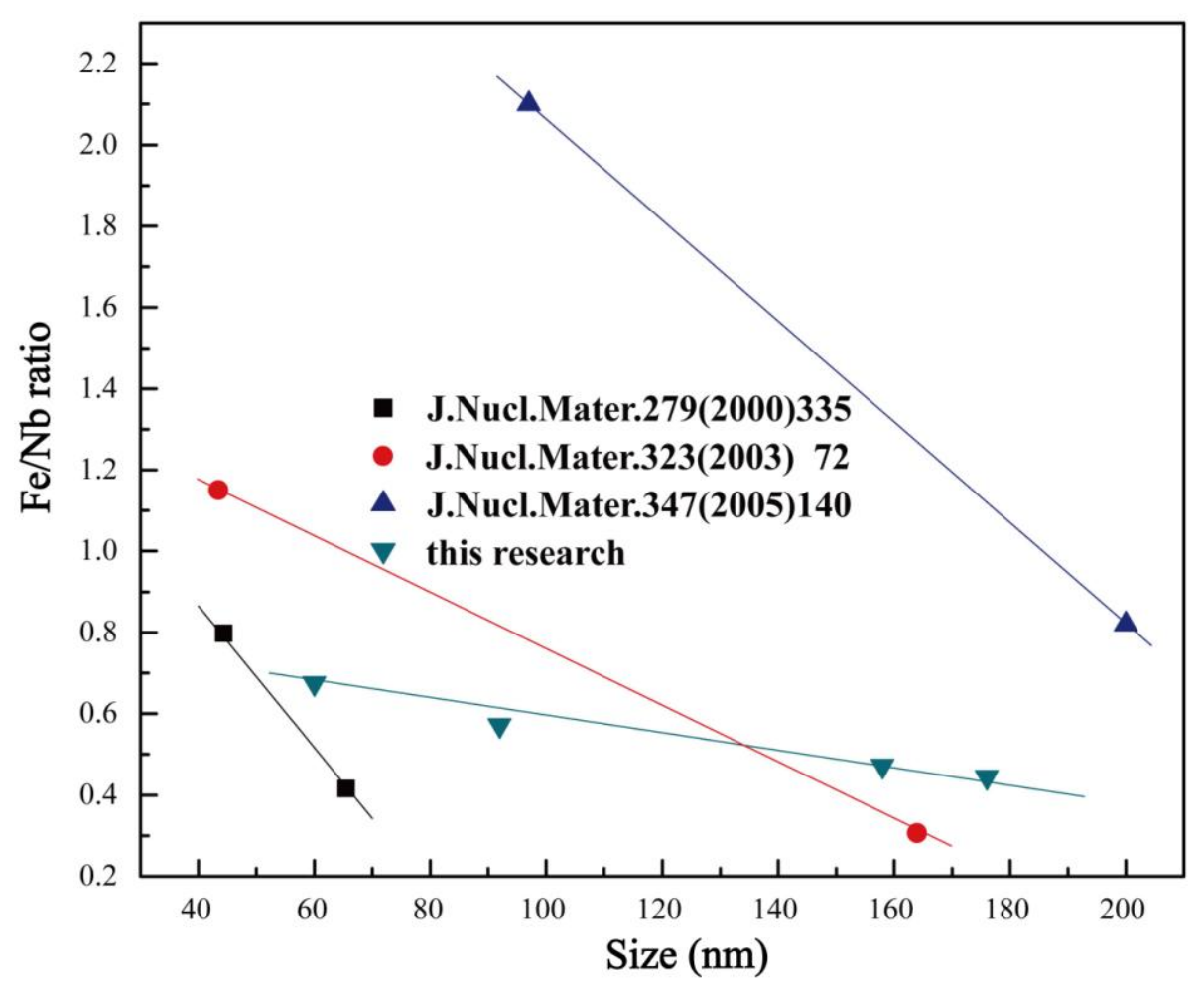

Fig. 7 

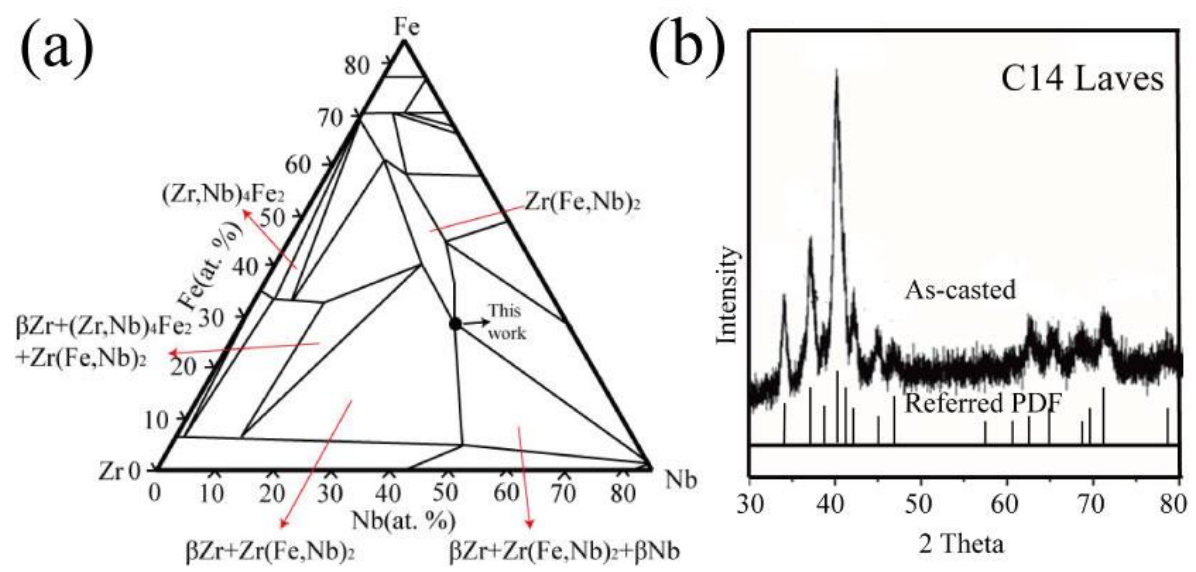

Fig. 8

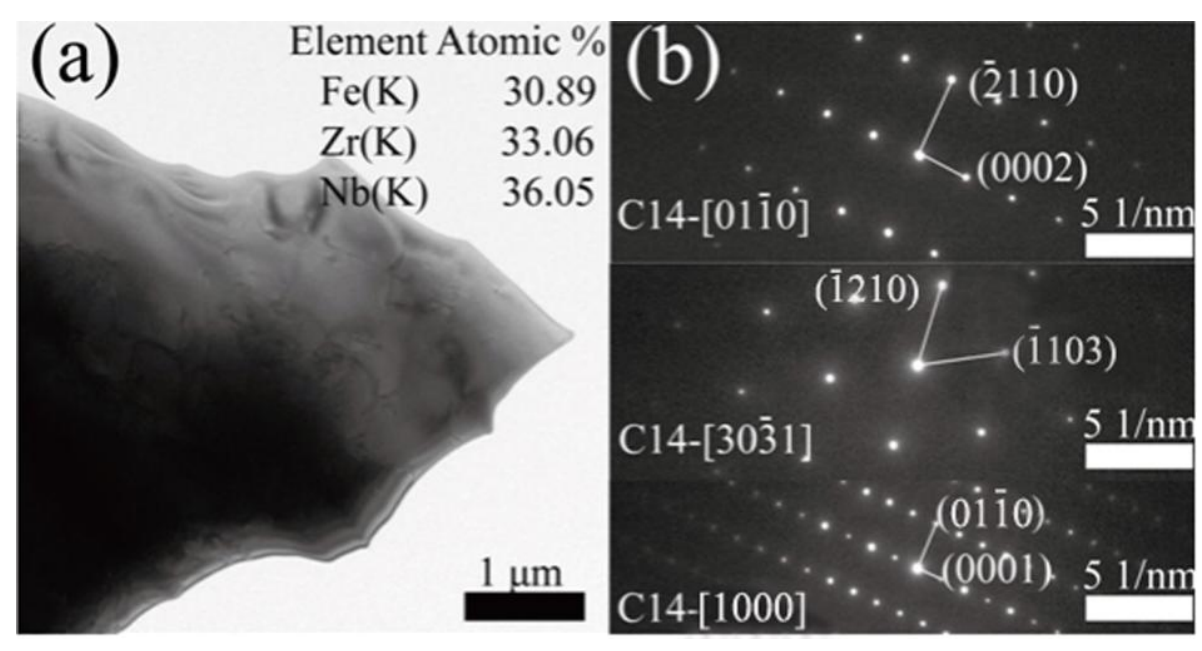

Fig. 9 


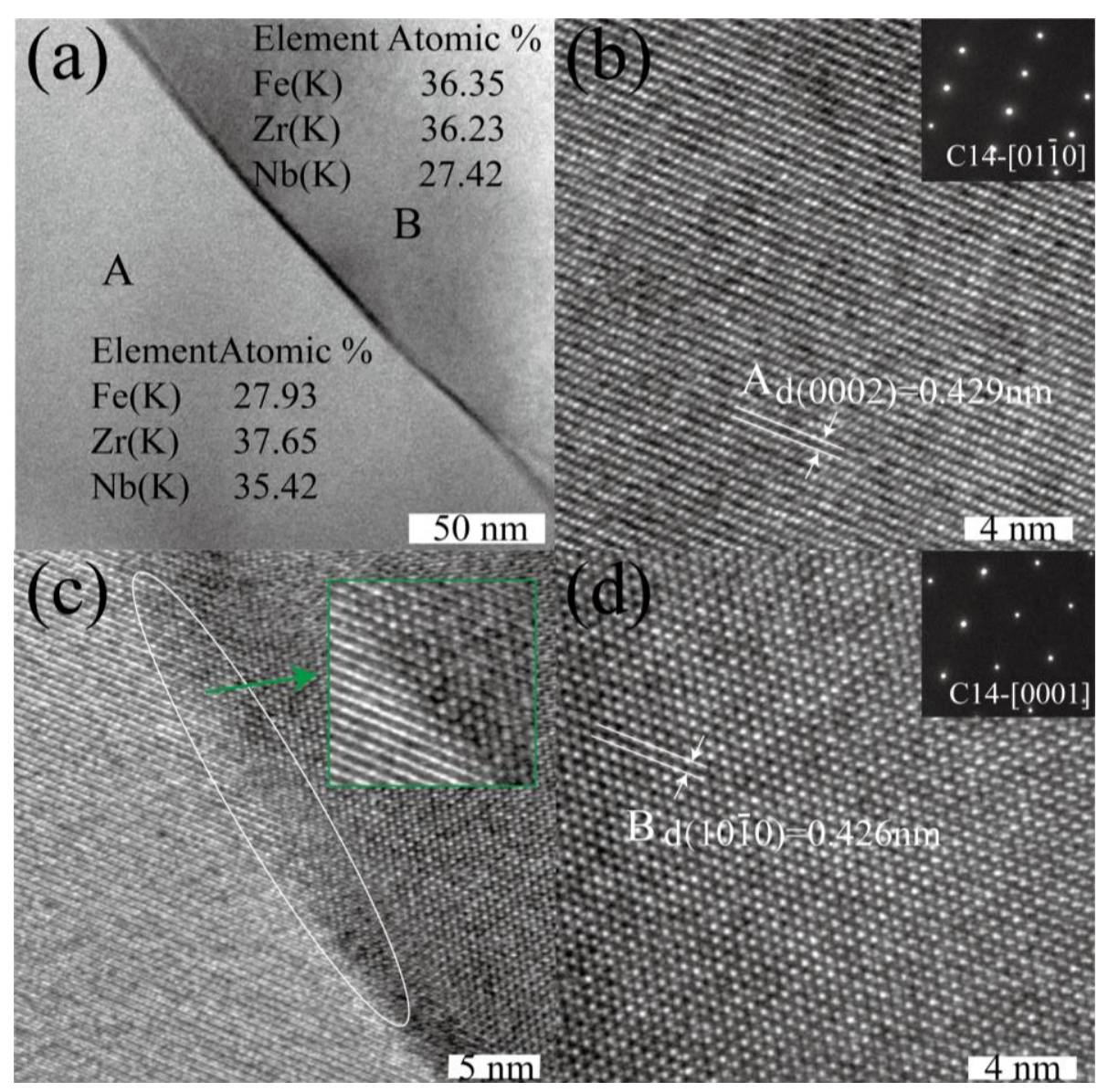

Fig. 10 